\title{
INTERNALIZATION OF NERVE GROWTH FACTOR BY PHEOCHROMOCYTOMA PC12 CELLS: ABSENCE OF TRANSFER TO THE NUCLEUS
}

\author{
H. ROHRER, T. SCHÄFER, S. KORSCHING, AND H. THOFNFN ${ }^{1}$ \\ Department of Neurochemistry, Max-Planck-Institute for Psychiatry, 8033 Martinsried/Munich, \\ Federal Republic of Germany
}

Received August 21, 1981; Revised November 12, 1981; Accepted January 5, 1982

\begin{abstract}
The intracellular distribution of ${ }^{125}$ I-labeled nerve growth factor (NGF) in rat pheochromocytoma PC12 cells was studied by quantitative electron microscopic (EM) autoradiography and by subcellular fractionation. PC12 cells were grown as monolayer cultures in medium supplemented with serum in the presence of ${ }^{125}$ I-NGF. EM autoradiography showed that ${ }^{125}$ I-NGF was localized at the plasma membrane and cytoplasmic compartments but did not accumulate in the nuclear chromatin or in the nuclear membrane compartment of cells analyzed after $1 \mathrm{hr}$ and 1,2 , and $8 \mathrm{~d}$ of incubation with ${ }^{125}$ I-NGF. ${ }^{125} \mathrm{I}-\mathrm{NGF}$ also was not detected in nuclear subcellular fractions prepared from cells grown in serum-supplemented medium either in suspension for $1 \mathrm{~d}$ or in monolayer cultures for 1 to $8 \mathrm{~d}$. In contrast, and in confirmation of the results of Yankner and Shooter (Yankner, B. A., and E. M. Shooter (1979) Proc. Natl. Acad. Sci. U. S. A. 76: 1269-1273), about $60 \%$ of the cell-bound ${ }^{125}$ INGF was found in the nuclear pellet after cell fractionation if the cells had been kept previously in suspension for $1 \mathrm{~d}$ in phosphate-buffered saline supplemented with $0.2 \%$ glucose, $0.1 \%$ bovine serum albumin, and ${ }^{125} \mathrm{I}-\mathrm{NGF}$. The ultrastructure of $\mathrm{PC} 12$ cells grown under such conditions, however, revealed signs of varying degrees of damage. Autoradiography of the nuclear pellet from these cells showed the grains to be located mainly over damaged nuclei or over cell debris between nuclei.

It is concluded that NGF, after binding to specific receptors at the plasma membrane, is transferred to membrane-confined cytoplasmic compartments but does not have to be transferred further to the nuclear membrane or to the nuclear chromatin as a prerequisite for its physiological action.
\end{abstract}

Nerve growth factor (NGF) is essential for the survival and differentiation of peripheral sympathetic and sensory neurons during restricted periods of their development and for the maintenance of function of differentiated sensory and sympathetic neurons and adrenal medullary cells (for review, see Greene and Shooter, 1980; Thoenen and Barde, 1980). In responsive neurons, NGF produces a variety of short term effects (such as the enhanced uptake of glucose and amino acids) as well as long term effects (e.g., the production of neurites and the specific increase in the synthesis of enzymes involved in transmitter synthesis). The binding of NGF to specific receptors on the cell surface has been demonstrated on all responsive cells tested and this ligand-receptor interaction is considered to be the initial step in the action of NGF. The binding of NGF to its receptors is followed by the clustering of the ligand-receptor complex and inter-

\footnotetext{
'To whom correspondence should be addressed at Department of Neurochemistry, Max-Planck-Institute for Psychiatry, Am Klopferspitz 18a, 8033 Martinsried/Munich, Federal Republic of Germany.
}

nalization by endocytosis (Levi et al., 1980). In rat sympathetic neurons, it has been demonstrated in vivo and in vitro that NGF is taken up into the nerve terminals by a selective and saturable mechanism and then is transferred to the perikaryon in membrane-confined compartments by retrograde axonal transport (Hendry et al., 1974a, b; Iversen et al., 1975; Johnson et al., 1978; Schwab and Thoenen, 1977; Dumas et al., 1979; Claude et al., 1979). In the cell body, at least some of the NGFcontaining vesicles and tubules fuse with lysosomes. Electron microscopic (EM) studies (quantitative autoradiography and histochemical localization of NGF covalently coupled to horseradish peroxidase) provided no evidence for a transfer of significant quantities of intact NGF from the membrane-confined compartments into the free cytoplasm and/or to the nucleus (Schwab, 1977; Schwab and Thoenen, 1977; Schwab et al., 1979; Claude et al., 1979). Recently, it has been reported, however, that a large proportion of NGF internalized by rat pheochromocytoma cells (PC12) is transferred to their nucleus, with the evidence being derived from cell fractionation 
experiments and light microscopic observations (Yankner and Shooter, 1979; Marchisio et al., 1980). PC12 cells are widely used as a model for sympathetic neurons as they respond to NGF with fiber outgrowth and increase in the specific activities of choline acetyltransferase and acetylcholinesterase (Greene and Tischler, 1976; Edgar and Thoenen, 1978; Greene and Rukenstein, 1981). In view of the discrepancy between the localization of internalized NGF in sympathetic neurons and in PC12 cells and considering its importance for future investigations on the molecular mechanism of action of NGF, we decided to analyze the subcellular localization of internalized ${ }^{125} \mathrm{I}-\mathrm{NGF}$ in $\mathrm{PC} 12$ cells in greater detail: it is important to know if NGF itself could be the intracellular messenger of its action at the nuclear membrane or in the nuclear chromatin as suggested by studies showing specific binding to isolated nuclei (Andres et al., 1977; Yankner and Shooter, 1979). If, on the other hand, such a specific association to the nucleus cannot be demonstrated in intact cells, then there would be a clear need to look for a second messenger which mediates the action of NGF.

The results of the present investigation demonstrated that, under regular cell culture conditions, NGF was localized at the plasma membrane and cytoplasmic compartments. No evidence for an accumulation of NGF in the nuclear membrane or in the nuclear chromatin of PC12 cells could be obtained either by quantitative EM autoradiography or by subcellular fractionation. When PC12 cells were incubated as suspension cultures for 24 $\mathrm{hr}$ in phosphate-buffered saline supplemented with $0.1 \%$ bovine serum albumin and $0.2 \%$ glucose (PBS/AG), the accumulation of about $60 \%$ of cell-bound ${ }^{125} \mathrm{I}-\mathrm{NGF}$ in the nuclear fraction previously reported (Yankner and Shooter, 1979) could be confirmed, but this nuclear accumulation was correlated with cell damage.

\section{Materials and Methods \\ Culture conditions}

PC12 cells (from Lloyd Greene, New York University School of Medicine) were cultured in Dulbecco's modified Eagle's medium supplemented with $10 \%(\mathrm{v} / \mathrm{v})$ horse serum, $5 \%(\mathrm{v} / \mathrm{v})$ fetal calf serum (both heat inactivated), $50 \mathrm{IU} / \mathrm{ml}$ of penicillin, and $50 \mu \mathrm{g} / \mathrm{ml}$ of streptomycin (hereafter described as "complete medium") on Falcon plastic tissue culture dishes. Cells were maintained at $37^{\circ} \mathrm{C}$ in a humidified $90 \%$ air, $10 \% \mathrm{CO}_{2}$ atmosphere. The culture medium was changed every $2 \mathrm{~d}$. The culture conditions used in the present experiments were identical to those used in previous studies in which the characteristic actions of NGF on PC12 cells were demonstrated, namely fiber outgrowth, enhanced adhesiveness, and selective enzyme induction (Schubert and Whitlock, 1977; Edgar and Thoenen, 1978).

\section{Preparation of ${ }^{125} I-N G F$}

NGF was purified according to the method of Bocchini and Angeletti (1969) as modified by Suda et al. (1978) and radioiodinated with lactoperoxidase according to Marchalonis (1969) as modified by Rohrer and Barde (1981). The specific activity of the ${ }^{125}$ I-NGF averaged 200 to $300 \mathrm{cpm} / \mathrm{pg}$ of NGF, corresponding to an incorporation of 2 or 3 molecules of ${ }^{125}$ I per NGF dimer. Ninety-two percent of the radioactivity appeared in the NGF band on 5 to $20 \%$ gradient polyacrylamide gel electrophoresis in the presence of SDS and $\beta$-mercaptoethanol. 'The iodinated NGF was as active as unlabeled NGF in the biological assay performed according to Fenton (1970) and in its ability to promote fiber outgrowth in PC12 cells. NGF was iodinated immediately before the start of each experiment and stored at the most for $6 \mathrm{~d}$ (in the case of 8-d incubations) before use.

\section{Binding studies}

Binding assays were carried out essentially as described by Yankner and Shooter (1979) with the modifications described below.

Monolayer cultures. PC12 cells $\left(6 \times 10^{5}\right.$ cells/35-mm dish) were incubated with $100 \mathrm{ng} / \mathrm{ml}$ of ${ }^{125} \mathrm{I}$-labeled NGF in complete medium at $37^{\circ} \mathrm{C}$ for 1,2 , and $8 \mathrm{~d}$. Neurite outgrowth in PC12 cells in response to labeled or unlabeled NGF was identical and followed a similar time course as described previously by Burstein and Greene (1978). Controls for nonspecific binding and internalization were performed by incubating cells with $100 \mathrm{ng} / \mathrm{ml}$ of ${ }^{125} \mathrm{I}-\mathrm{NGF}$ and $10 \mu \mathrm{g} / \mathrm{ml}$ of unlabeled NGF. After the incubation, the medium was replaced by $800 \mu \mathrm{l} / \mathrm{dish}$ of Dulbecco's phosphate-buffered saline containing $0.1 \%$ bovine serum albumin (Sigma) and $0.2 \%$ glucose (PBS/ $\mathrm{AG}$ ), and the cells were dislodged from the dish by trituration in the same solution. Three hundred-microliter aliquots of the cell suspension were added to $200 \mu \mathrm{l}$ of PBS/AG containing $20 \mu \mathrm{g} / \mathrm{ml}$ of unlabeled NGF in the presence or absence of $2.5 \%(\mathrm{v} / \mathrm{v})$ Triton X-100, and the solutions were incubated for $5 \mathrm{~min}$ at $37^{\circ} \mathrm{C}$. Thereafter, 150- $\mu \mathrm{l}$ aliquots were centrifuged through a two-step sucrose gradient and rapidly frozen (Yankner and Shooter, 1979). The radioactivity in both the pellet and the supernatant was determined. To correct for the loss of cells during medium changes from cultures kept for $8 \mathrm{~d}$ either in the presence of $100 \mathrm{ng} / \mathrm{ml}$ of ${ }^{125} \mathrm{I}-\mathrm{NGF}$ or in $10 \mu \mathrm{g} / \mathrm{ml}$ of unlabeled NGF and $100 \mathrm{ng} / \mathrm{ml}$ of ${ }^{125} \mathrm{I}-\mathrm{NGF}$, the cell number was determined after harvesting and dispersal to single cells.

Suspension cultures. PC12 cells grown in monolayer cultures were harvested by trituration and incubated at $37^{\circ} \mathrm{C}$ at a cell density of $6 \times 10^{5}$ cells $/ \mathrm{ml}$ in $35-\mathrm{mm}$ bacteriological dishes on a rotary shaker at $35 \mathrm{rpm}$ with 5 or $100 \mathrm{ng} / \mathrm{ml}$ of ${ }^{125} \mathrm{I}-\mathrm{NGF}$ either in complete medium or in PBS/AG. Control cultures contained $10 \mu \mathrm{g} / \mathrm{ml}$ of unlabeled NGF in addition to the ${ }^{125} \mathrm{I}-\mathrm{NGF}$. After incubation, the cells were harvested by centrifugation, resuspended in PBS/AG, and then chased and assayed for ${ }^{125}$ I-NGF binding to intact cells or to nuclear fractions as described for monolayer cultures. Identical results were obtained when the centrifugation step was omitted.

\section{EM autoradiography}

Preparation of cultures for EM and autoradiography. Cultures of PC12 cells at a density of $4 \times 10^{5}$ cells/35$\mathrm{mm}$ dish were incubated with $100 \mathrm{ng} / \mathrm{ml}$ of ${ }^{1225} \mathrm{I}-\mathrm{NGF}$ in complete medium. Controls for nonspecific binding and internalization were performed by incubating the cells with complete medium containing $10 \mu \mathrm{g} / \mathrm{ml}$ of unlabeled 
NGF in addition to the ${ }^{125}$ T-NGF. The cells were incubated for $1 \mathrm{hr}$ and 1,2 , and $8 \mathrm{~d}$ with the medium changed daily (in the case of 2-d incubations) or every other day (in the case of 8-d incubations). After these times, the cultures were washed twice with complete medium at room temperature and then fixed in silu with $1.5 \%$ glutaraldehyde and $1.5 \%$ formaldehyde in $0.1 \mathrm{~m}$ phosphate buffer, $\mathrm{pH} 7.4$, for $2 \mathrm{hr}$ at room temperature. The cultures were washed overnight in $0.1 \mathrm{M}$ phosphate buffer, $\mathrm{pH} 7.4$, postfixed with $1 \% \mathrm{OsO}_{4}$, dehydrated, and embedded in Epon 812. For each time point, from six randomly chosen blocks, thin sections were cut parallel to the dish, mounted onto one-hole grids supported with Pioloform films (Wacker Chemie, München), and prepared for autoradiography. The emulsion (Ilford L4, diluted 1:1 with $\mathrm{H}_{2} \mathrm{O}$ ) was applied to the sections using a platinum loop as described by Caro and Van Tubergen (1962). After the emulsion was dry, the sections were exposed at $4^{\circ} \mathrm{C}$ in a desiccated atmosphere for 4 months. Autoradiographs were developed with Microdol-X (Eastman Kodak) for 3 min and fixed with $24 \%$ sodium thiosulfate for $5 \mathrm{~min}$. After careful washing with $\mathrm{H}_{2} \mathrm{O}$, the sections were stained with uranyl acetate and lead citrate and examined in a Zeiss EM10 electron microscope operated at $40 \mathrm{kV}$. Electron micrographs were printed at a final magnification of $\times 18,700$.

Cells grown in suspension or isolated nuclear fractions were prepared for EM as described above with the following modifications: intact cells were harvested by centrifugation after incubation with $100 \mathrm{ng} / \mathrm{ml}$ of ${ }^{125} \mathrm{I}-\mathrm{NGF}$ in PBS/AG or in complete medium. Cellular and nuclear pellets were fixed in the centrifugation tubes. After washing and osmification, the pellets were removed from the tubes, dehydrated, and embedded in flat molds. They were processed further as described for monolayer cultures.

Sampling and analysis of autoradiography data. For experiments in which cells were incubated with ${ }^{125} \mathrm{I}-\mathrm{NGF}$ alone (total binding), 500 to 600 grains were analyzed on a total of 20 to 60 randomly selected micrographs with 40 to 100 cells for each incubation time $(1 \mathrm{hr}$ and 1,2 , and $8 \mathrm{~d}$ ). For experiments in which the distribution of nonspecifically bound and then internalized ${ }^{125}$ I-NGF was analyzed, the density of silver grains was 5- to 10 -fold lower than in the analysis of total binding. Thus, only about 350 grains could be analyzed in these control experiments (nonspecific binding) after incubation times of 1 or $2 \mathrm{~d}$, and about 100 grains could be analyzed after incubation times of $1 \mathrm{hr}$ or $8 \mathrm{~d}$.

Quantitative evaluation. The distribution of silver grains over the plasma membrane, the nuclear membrane, and the remaining regions of cytoplasm and nucleus was assessed in the following manner: the distance between the center of the grain, as determined by encircling the grain (Fig. 1), and the closest nuclear membrane or plasma membrane was determined. Grains situated within a distance of $270 \mathrm{~nm}$ from the plasma membrane or from the nuclear membrane-a distance assumed to include more than $80 \%$ of the grains related to a line source of radiation (Salpeter et al., 1977)-were attributed to the compartments of plasma membrane, outside $\left(\mathrm{Pm}_{0}\right)$ or inside $\left(\mathrm{Pm}_{\mathrm{i}}\right)$, or to compartments of nuclear membrane, outside $\left(\mathrm{Nm}_{\mathrm{o}}\right)$ or inside $\left(\mathrm{Nm}_{\mathrm{i}}\right)$ (see Fig. 1). Grains located within the cytoplasmic or nuclear area at a distance greater than $270 \mathrm{~nm}$ from the plasma membrane or nuclear membrane were assigned to the residual cytoplasmic compartments (RCC) or the nuclear compartment (N). Grains attributable to two compartments were distributed to these individual compartments according to the relative proportions of grains that could be rigorously (center of the circle in only one compartment) allotted to these individual compartments. Such "shared" grains were only a minor proportion of the total in every compartment except in that of the outer nuclear membrane where between 20 and $33 \%$ of the grains also could be allotted to the inner plasma membrane (see Fig. $1 b$ ). The percentage of grains attributed to each compartment was determined for both total and nonspecific ${ }^{125} \mathrm{I}-\mathrm{NGF}$ internalizations. The proportion of specific grains for each compartment then was obtained by subtracting the percentage of nonspecific grains from that of total grains after correcting for the lower grain density over cells from nonspecific ${ }^{125} \mathrm{I}-\mathrm{NGF}$ internalization. ${ }^{125} \mathrm{I}-$ NGF bound and internalized nonspecifically represents between 11 and $26 \%$ of the total grains. The distribution of grains due to nonspecifically bound ${ }^{125} \mathrm{I}-\mathrm{NGF}$ is very similar to the cellular distribution of the total bound and internalized NGF: between 91 and $95 \%$ of all grains are located over the plasma membrane and residual cytoplasmic compartments $\left(\mathrm{Pm}_{\mathrm{o}}, \mathrm{Pm}_{\mathrm{i}}\right.$, and $\left.\mathrm{RCC}\right)$.

The relative proportions of the areas of the six compartments defined above were calculated from the electron micrographs with the aid of a digitizing device (Hewlett-Packard S9245). For each compartment, the grain density was obtained by dividing its percentage of the specific grain number by its percentage of the total area.

\section{Results}

\section{Subcellulur distribution of ${ }^{125} I-N G F$ : Quantitative analysis by EM autoradiography in PC12 cells in monolayer culture}

When PC12 cells were incubated at $37^{\circ} \mathrm{C}$ with ${ }^{125} \mathrm{I}$ NGF for time periods between $1 \mathrm{hr}$ and $8 \mathrm{~d}$ in medium supplemented with serum, about $90 \%$ of the specifically bound and internalized NGF - detected by silver grainscan be attributed to the compartments of plasma membrane and residual cytoplasm $\left(\mathrm{Pm}_{\mathrm{o}}, \mathrm{Pm}_{\mathrm{i}}\right.$, and $\mathrm{RCC}$ ) (Fig. 2; Table I). The proportion of grains originating from ${ }^{125}$ I-NGF specifically bound and internalized which are located over the nucleus $\left(\mathrm{Nm}_{\mathrm{i}}\right.$ and $\left.\mathrm{N}\right)$ is small and varies between 1 and $6 \%$. If the nucleus would be freely accessible to NGF, then the proportion of total grains in these compartments should be as high as the relative proportion of their areas. The proportion of grains is, however, much lower than the ratio of the nuclear area to the total cellular area: the relative grain densities over the compartments of the nuclear membrane $\left(\mathrm{Nm}_{\mathrm{i}}\right)$ and nucleus (N) are far below 1, indicating that ${ }^{125}$ I-NGF certainly is not enriched in these compartments. Grains in the compartments of the nuclear membrane can be due to NGF bound to the nuclear membrane-about $80 \%$ of the grains due to a radiation source in the membrane will lie within 

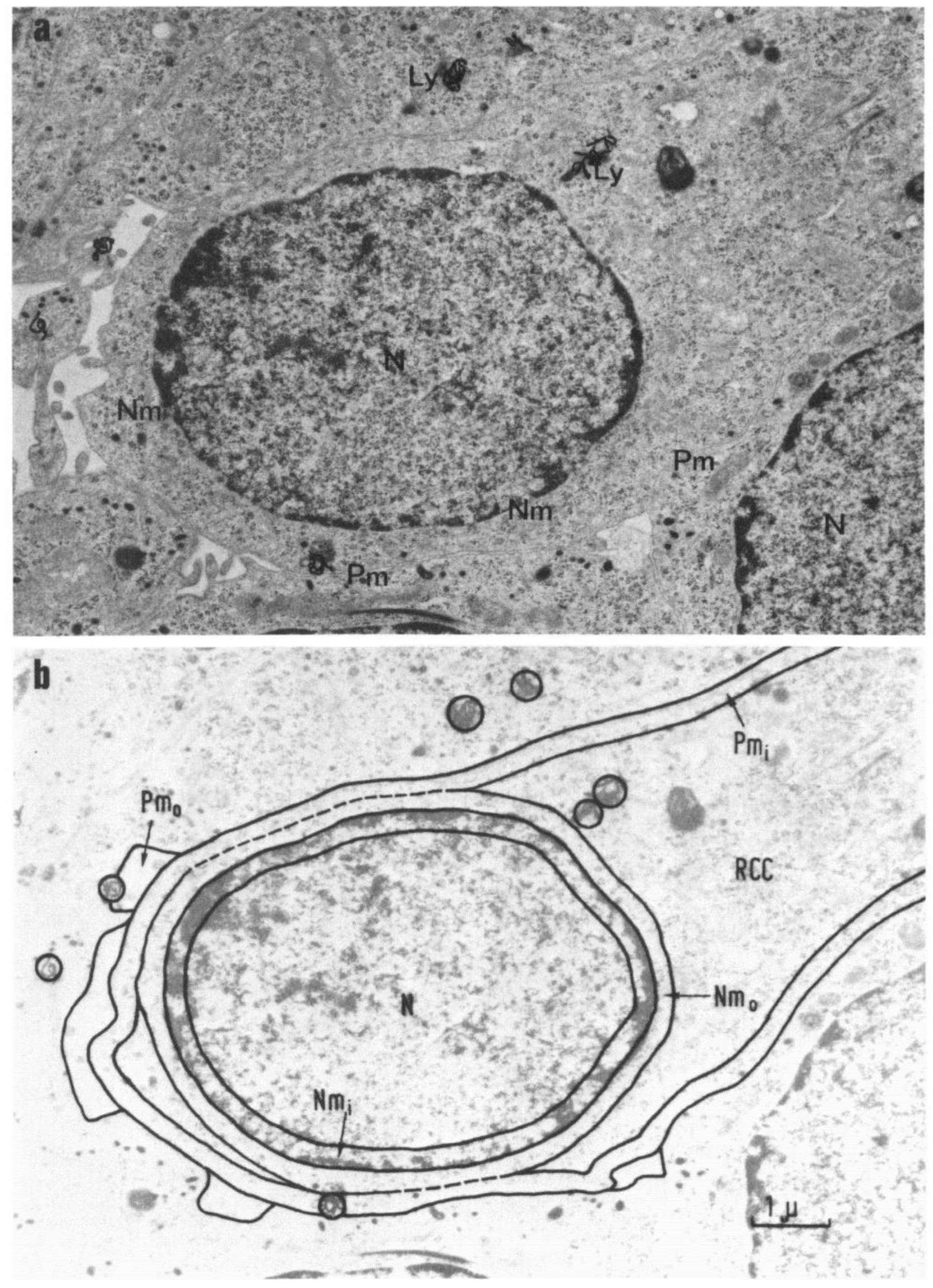

Figure 1. Electron microscopic autoradiography from PC12 cells incubated with $100 \mathrm{ng} / \mathrm{ml}$ of ${ }^{125} \mathrm{I}$-NGF for $1 \mathrm{~d}$ in medium supplemented with serum. $a$, Typical autoradiograph showing silver grains over lysosomes $(L y)$ and plasma membrane $(P m)$. Note the absence of grains over the nucleus $(N)$ and nuclear membrane $(\mathrm{Nm}) . b$, Same autoradiograph with a schematic drawing of the compartments chosen for statistical evaluation of the grain distribution: the distance between the plasma membrane or nuclear membrane and the compartment boundary is $270 \mathrm{~nm}$. The dashed lines indicate the overlapping of two compartments. $\mathrm{N}$, nucleus; $\mathrm{Nm}_{o}$ and $\mathrm{Nm} m_{i}$, nuclear membrane outside and inside; $\mathrm{Pm}_{o}$ and $\mathrm{Pm} \mathrm{m}_{i}$, plasma membrane outside and inside; RCC, residual cytoplasmic compartments. Bar, $1 \mu \mathrm{m}$. 


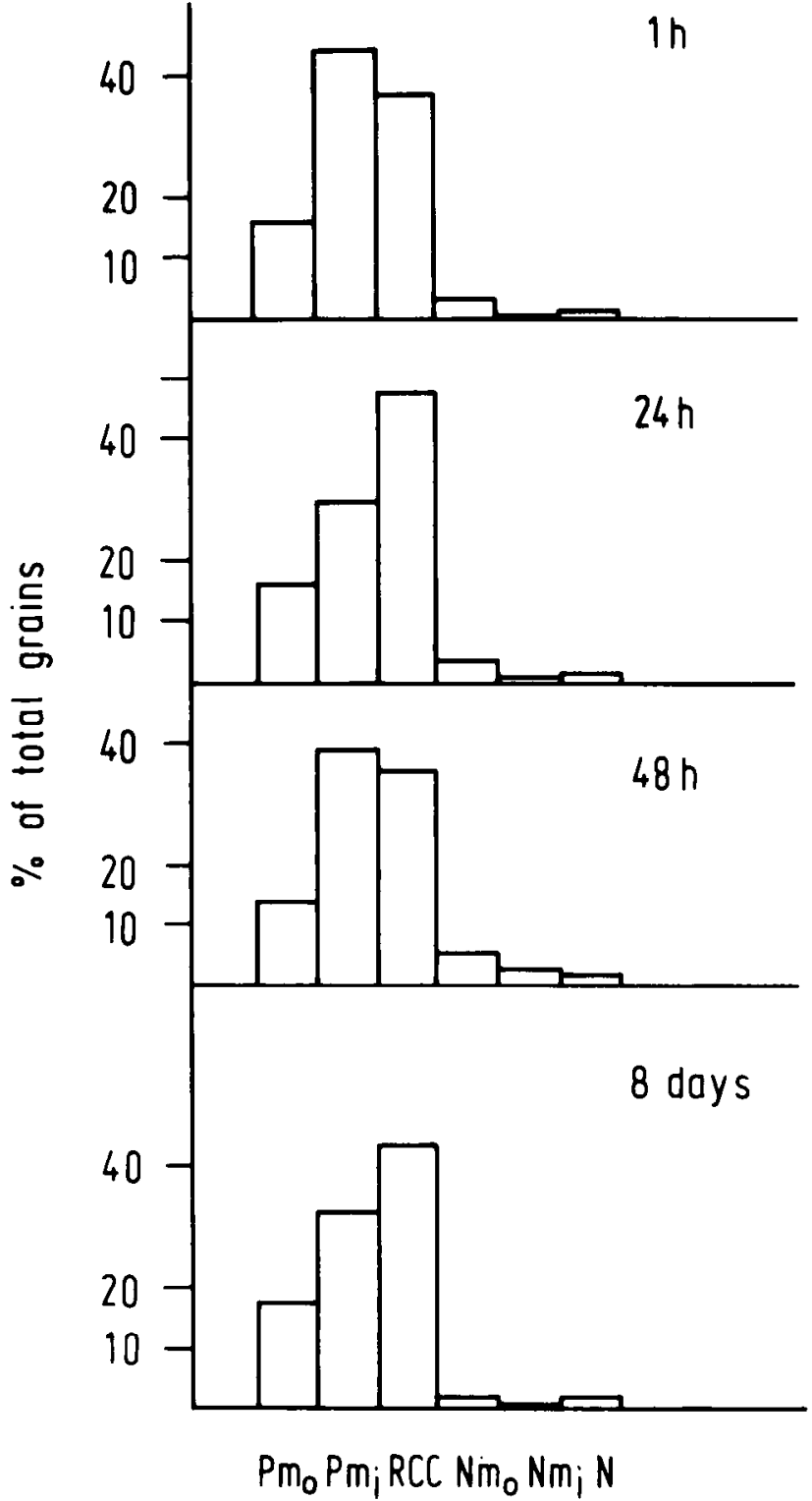

Figure 2. Distribution of silver grains over different compartments after incubation of PC12 cells with $100 \mathrm{ng} / \mathrm{ml}$ of ${ }^{125} \mathrm{I}-$ NGF. The number of grains over different compartments resulting from the specific internalization of ${ }^{125} \mathrm{I}-\mathrm{NGF}$ after $1 \mathrm{hr}$ and 1,2 , and $8 \mathrm{~d}$ of incubation was determined as indicated under "Materials and Methods."

a distance of $270 \mathrm{~nm}$ from the membrane (Salpeter et al., 1977) - but also can be due to NGF in cytoplasmic organelles within a distance of $540 \mathrm{~nm}$ from the membrane. If all of the grains in this compartment would originate from NGF bound to the nuclear membrane, the grains would show a symmetrical distribution over the membrane. The analysis of the grain distribution over the nuclear membrane showed, however, a markedly asymmetrical distribution. The result is presented in the form of a histogram with a class width of $54 \mathrm{~nm}$ (Fig. 3). The asymmetrical distribution of grains over the nuclear membrane indicates that only a small proportion of the grains classified in the nuclear membrane compartments $\left(\mathrm{Nm}_{\mathrm{o}}\right.$ and $\left.\mathrm{Nm}_{\mathrm{i}}\right)$ are due to label actually present in the nuclear membrane. The proportion of grains classified in $\mathrm{Nm}_{\mathrm{o}}$ and $\mathrm{Nm}_{\mathrm{i}}$ thus represents an overestimation due to the localization of large amounts of NGF in vesicles and lysosomes (Figs. $1 a$ and 4 ) situated in close proximity to the nuclear membrane.

\section{Cellular distribution of internalized ${ }^{125} I-N G F$ : Analysis by cell fractionation}

Monolayer cultures in medium supplemented with serum. Between $26 \times 10^{3}$ and $51 \times 10^{3} \mathrm{NGF}$ molecules/ cell are specifically bound and internalized after the incubation of PC12 cells with ${ }^{125} \mathrm{I}-\mathrm{NGF}$ in monolayer cultures for 1 to $8 \mathrm{~d}$ (Table II). The smaller number of NGF molecules present per cell after incubation for $8 \mathrm{~d}$ compared to that after 2 and $3 \mathrm{~d}$ incubation might be due to an enhanced degradation of ${ }^{125} \mathrm{I}$-NGF since these cells contain a higher number of large membrane-containing lysosomes (compare Fig. $1 a$ with Fig. 4). These values are not corrected for the degradation of NGF in the cells (see below) and thus are higher than the actual number of intact NGF molecules per cell. When the distribution of internalized ${ }^{125}$ I-NGF was analyzed by the cell fractionation procedure described by Yankner and Shooter (1979) after 1, 2, 3, and $8 \mathrm{~d}$ of incubation with ${ }^{125}$ I-NGF, the proportion of NGF present in the nuclear fraction varied between 0.5 and $2 \%$, reaching statistically significant levels $(p<0.05)$ at only one time point, namely $24 \mathrm{hr}$ (Table II).

Suspension cultures in medium supplemented with serum. In order to analyze the influence of the culture conditions on the subcellular distribution of ${ }^{125} \mathrm{I}-\mathrm{NGF}$, we incubated PC12 cells in suspension instead of under monolayer conditions in complete medium with ${ }^{125}$ I-NGF for $1 \mathrm{~d}$ : the amount of NGF detectable in the nuclear fraction (Table II) was small and again did not reach significant levels.

Suspension cultures in phosphate-buffered saline supplemented with $0.1 \%$ bovine serum albumin and $0.2 \%$ glucose (PBS/AG). When suspension cultures of $\mathrm{PC} 12$ cells were incubated with ${ }^{125} \mathrm{I}$-NGF in phosphate-buffered saline supplemented with $0.1 \%$ bovine serum albumin and $0.2 \%$ glucose (PBS/AG) instead of complete medium, a large proportion of the radioactivity was detected in the nuclear fraction: $60 \%$ after incubation with $100 \mathrm{ng} /$

\section{TABLE I}

Relative grain density over different compartments of $P C 12$ cells after different times of incubation with ${ }^{125} I-N G F$ in medium supplemented with serum

For the definition of the compartments and the evaluation of the relative grain densities, see Figure $1 a$ and "Materials and Methods."

\begin{tabular}{lcccc}
\hline \multirow{2}{*}{ Compartment } & \multicolumn{4}{c}{ Time } \\
\cline { 2 - 4 } & $1 \mathrm{hr}$ & $1 \mathrm{~d}$ & $2 \mathrm{~d}$ & $8 \mathrm{~d}$ \\
\hline Plasma membrane & & & & \\
$\quad$ Outside & 2.6 & 1.6 & 2.3 & 3.6 \\
$\quad$ Inside & 2.7 & 2.0 & 2.3 & 2.6 \\
Residual cytoplasmic & 1.1 & 1.1 & 1.1 & 1.0 \\
$\quad$ & & & & \\
Nuclear membrane & 0.4 & 0.7 & 0.7 & 0.5 \\
$\quad$ Outside & 0.1 & 0.2 & 0.4 & 0.1 \\
$\quad$ Inside & & & & \\
$\quad$ Residual nuclear & 0.1 & 0.1 & 0.1 & 0.1 \\
\hline
\end{tabular}




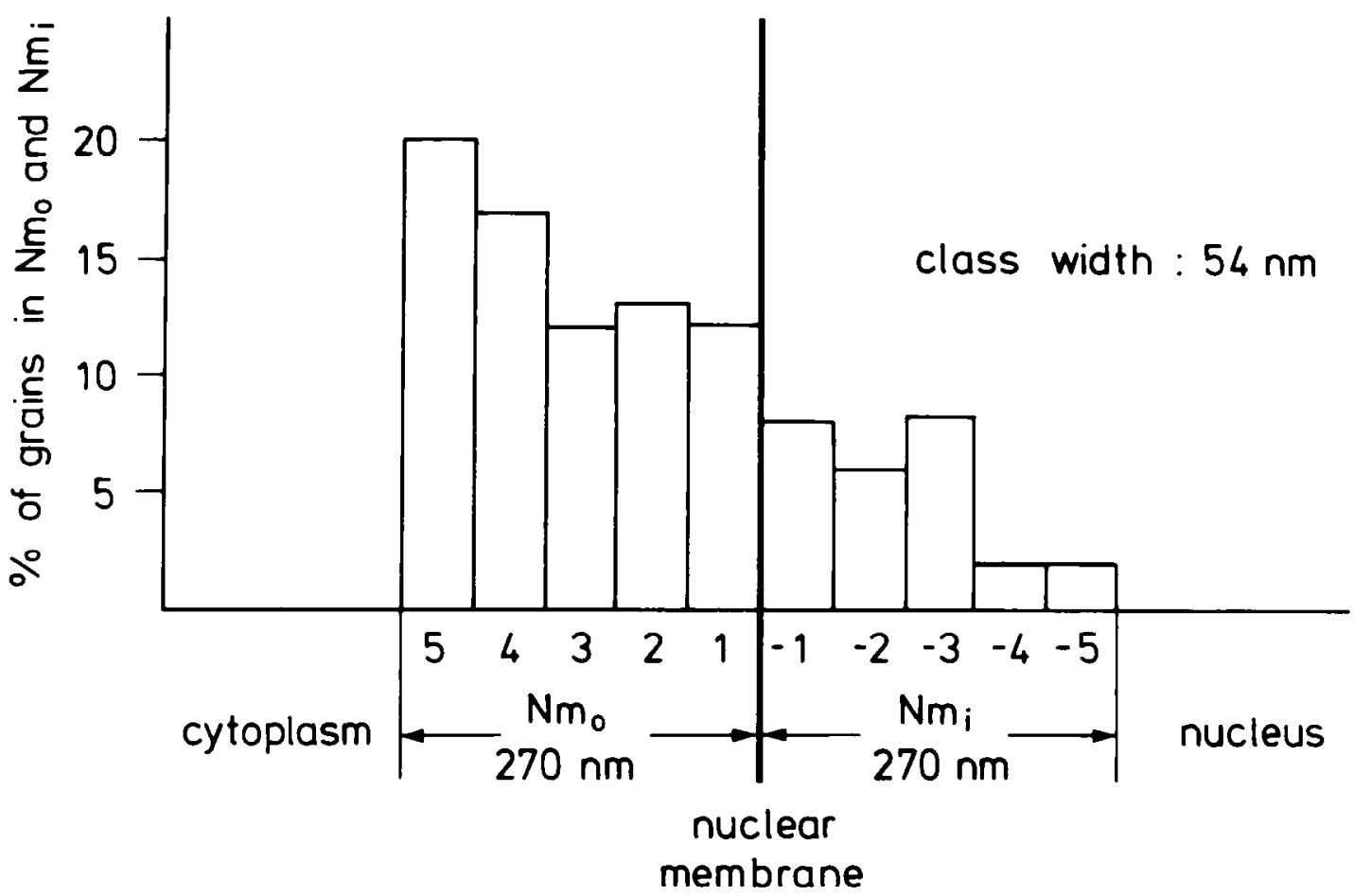

Figure 3. Detailed analysis of the location of silver grains within the nuclear compartments $\mathrm{Nm}_{\circ}$ or $\mathrm{Nm}_{\mathrm{i}}$. PC12 cells were incubated with $100 \mathrm{ng} / \mathrm{ml}$ of ${ }^{125} \mathrm{I}-\mathrm{NGF}$ for $2 \mathrm{~d}$ in medium supplemented with serum. The small proportion of grains with centers within $270 \mathrm{~nm}$ on either side of the nuclear membrane (see Fig. 2) have been analyzed further and presented in a histogram showing the percentage of grains belonging to five classes with a 54-nm widh on either side of the nuclear membrane. Of the more than 250 cells analyzed, the 90 grains meeting this criterion are distributed unevenly: $25 \%$ are localized inside (in $\mathrm{Nm}_{\mathrm{i}}$ ) and $75 \%$ are localized outside (in $\mathrm{Nm}_{0}$ ) of the nuclear membrane. This asymmetry speaks against the assumption that the source of radiation of the grains attributable to $\mathrm{Nm}_{\mathrm{i}}$ and $\mathrm{Nm}_{\mathrm{o}}$ lies in the nuclear membrane.

$\mathrm{ml}$ of ${ }^{125} \mathrm{I}-\mathrm{NGF}$ and $25 \%$ with $5 \mathrm{ng} / \mathrm{ml}$ of ${ }^{125} \mathrm{I}-\mathrm{NGF}$ (Table II).

\section{Morphology of cells and nuclear fractions after suspension culture in phosphate-buffered saline supplemented with bovine serum albumin and glucose}

The morphology of PC12 cells cultured in suspension in PBS/AG clearly differs from that in medium supplemented with serum: under the former conditions, the chromatin is condensed and the space between the inner and outer nuclear membrane is dilated in a large proportion of cells after $1 \mathrm{~d}$ (Fig. $5 a$ ). Between 1 and $2 \mathrm{~d}$ in culture, the majority of cells kept in PBS/AG died so that only very few cells-with the same signs of damage (Fig. 5c)-were recovered. However, the cell number did not decrease between 1 and $2 \mathrm{~d}$ in suspension culture when medium supplemented with serum was used (data not shown). Under these latter culture conditions, the cells showed the same morphological features as did cells in monolayer culture (Fig. $5, b$ and $d$ ). Nuclear pellets from cells kept in PBS/AG for $1 \mathrm{~d}$ consisted of intact and broken nuclei. Grains were located over damaged nuclei and over debris between nuclei to a much larger extent than over intact nuclei (Fig. 6). In view of the obvious damage to the cells kept in PBS/AG, a quantitative EM autoradiographic analysis of whole cells and of nuclear fractions was not performed.

\section{Degradation of ${ }^{125} I-N G F$ in PC12 cells}

Both for the EM autoradiography and for the binding studies, it is important to know to what extent the radioactivity measured (grains or counts) reflects intact ${ }^{125} \mathrm{I}-\mathrm{NGF}$ or degradation products. In the case of the autoradiography, an additional variable exists because it is uncertain to what extent the degradation products can be fixed by the glutaraldehyde/formaldehyde solution. To analyze both the extent of degradation of ${ }^{125} \mathrm{I}-\mathrm{NGF}$ and the efficiency of the fixation procedure, $\mathrm{PC} 12$ cells were harvested after $24 \mathrm{hr}$ incubation with ${ }^{125} \mathrm{I}-\mathrm{NGF}$, and the suspension was divided into two portions. One aliquot was lysed by SDS and analyzed by SDS-polyacrylamide gel electrophoresis. The radioactivity present in the NGF band corresponded to $66 \pm 4 \%$ of the total radioactivity detected in the gel (Fig. 7). The other aliquot of the cell suspension was fixed, washed, postfixed, and dehydrated as for EM autoradiography. After the last dehydration step, $66 \pm 3 \%$ of the radioactivity present in the cells following incubation remained. These results are consistent with the assumption that the radioactive degradation products of ${ }^{125}$ I-NGF $\left({ }^{125}\right.$ I-tyrosine and/or small peptides; see Fig. 7) are not fixed by the procedure used for EM autoradiography. Thus, most of the grains analyzed are due to intact NGF. Since the medium containing ${ }^{125} \mathrm{I}$-NGF was changed every 1 to $2 \mathrm{~d}$ (see "Materials and Methods"), the number of NGF molecules per cell 
(Table II) reflects steady state levels due to the binding, internalization, and degradation of ${ }^{125} \mathrm{I}-\mathrm{NGF}$.

\section{Discussion}

It was the aim of the present investigation to evaluate whether the subcellular distribution of internalized NGF in PC12 cells is different from that in sympathetic neurons since previous studies, using different methods, had provided conflicting information. On the one hand, quantitative EM autoradiography and histochemistry of sympathetic neurons indicated a localization of internalized $\mathrm{NGF}$ in cytoplasmic membrane-confined compartments



Figure 4. Electron microscopic autoradiograph from $\mathrm{PC} 12$ cells incubated with $100 \mathrm{ng} / \mathrm{ml}$ of ${ }^{125} \mathrm{I}-\mathrm{NGF}$ for $8 \mathrm{~d}$ in medium supplemented with serum. The cells do not show any signs of degeneration but extend long neurites. Note the high number of silver grains over the large membrane-containing lysosomes. Magnification $\times 14,000$.

TABLE II

Influence of culture conditions on the proportion of bound and internalized ${ }^{125}$ I-NGF related to the nuclear fraction The values given represent the mean \pm SEM.

\begin{tabular}{|c|c|c|c|c|c|c|}
\hline $\begin{array}{l}{ }^{12 \pi} \mathrm{I}-\mathrm{NGF} \\
\text { Concentration }\end{array}$ & $\begin{array}{l}\text { Incubation } \\
\text { Time }\end{array}$ & Culture Conditions & $\begin{array}{l}\text { No. Independent } \\
\text { Measurements }\end{array}$ & \multicolumn{2}{|c|}{$\begin{array}{c}\text { No. NGF } \\
\text { Molecules/Cell }\end{array}$} & $\begin{array}{c}\text { Proportion of NGF } \\
\text { Related to Nuclear } \\
\text { Fraction }\end{array}$ \\
\hline$n g / m l$ & $d$ & & & & & $\%$ \\
\hline 5 & 1 & $\begin{array}{c}\text { Suspension; PBS, } 0.2 \% \text { glucose, } \\
0.1 \% \mathrm{BSA}^{\alpha}\end{array}$ & 4 & $6 \pm 1$ & $\times 10^{3}$ & $25 \pm 10$ \\
\hline 100 & 1 & $\begin{array}{c}\text { Suspension; PBS, } 0.2 \% \text { glucose, } \\
0.1 \% \mathrm{BSA}\end{array}$ & 8 & $63 \pm 12$ & $\times 10^{3}$ & $59 \pm 17$ \\
\hline 100 & 1 & Suspension; complete medium & 15 & $20 \pm 2$ & $\times 10^{3}$ & $4 \pm 6^{b}$ \\
\hline 100 & 1 & Monolayer; complete medium & 10 & $26 \pm 2$ & $\times 10^{3}$ & $2.2 \pm 0.6$ \\
\hline 100 & 2 & Monolayer; complete medium & 5 & $49 \pm 3$ & $\times 10^{3}$ & $0.8 \pm 0.5^{b}$ \\
\hline 100 & 3 & Monolayer; complete medium & 5 & $51 \pm 4$ & $\times 10^{3}$ & $0.5 \pm 0.4^{b}$ \\
\hline 100 & 8 & Monolayer; complete medium & 5 & $34 \pm 3$ & $\times 10^{3}$ & $0.5 \pm 4^{b}$ \\
\hline
\end{tabular}

${ }^{a}$ BSA, bovine serum albumin.

${ }^{b}$ Not significantly different from $0(p<0.05)$. 

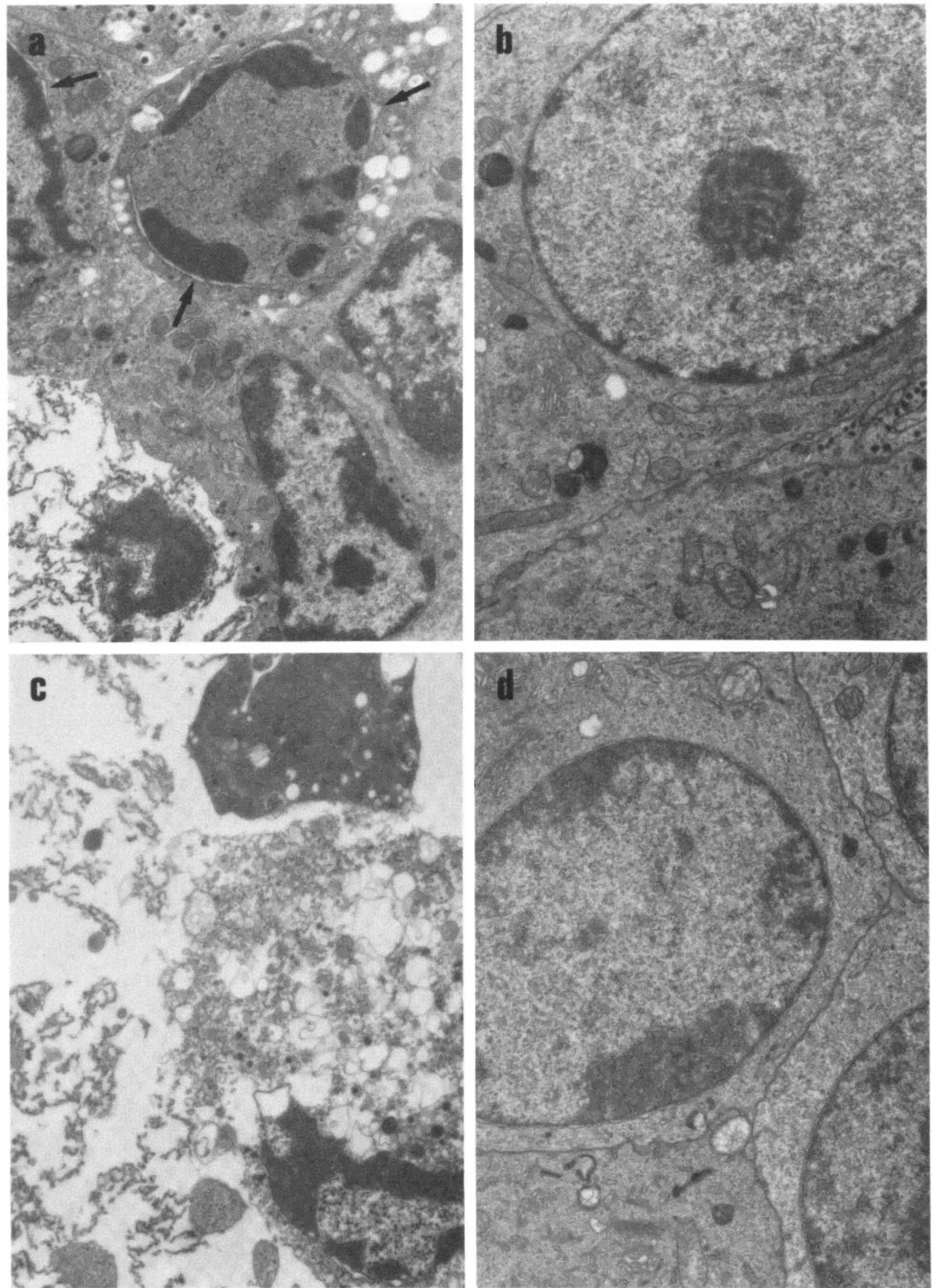

Figure 5. Electron micrographs of PC12 cells grown with $100 \mathrm{ng} / \mathrm{ml}$ of NGF in suspension culture either in PBS/AG $(a$ and $c$ ) or in medium supplemented with serum $(b$ and $d)$. Cells were cultured for $1(a$ and $b)$ or $2 \mathrm{~d}(c$ and $d)$ and then harvested by centrifugation and processed for electron microscopy as indicated under "Materials and Methods." Cells grown in medium supplemented with serum had a normal morphological appearance, compared to cells grown under monolayer conditions, after 1 $\mathrm{d}(b)$ as well as after $2 \mathrm{~d}(d)$ or $3 \mathrm{~d}$ (not shown). In contrast, cells do not survive at all for $3 \mathrm{~d}$ in PBS/AG. Already after $1 \mathrm{~d}$ and even more after $2 \mathrm{~d}$, a large proportion of the cells have degenerated. The remaining cells show signs of severe damage in the form of abnormal condensation of chromatin, formation of vacuoles (in $a$ ), dilatation of the nuclear membrane (arrows), and breaking up of plasma membrane followed by loss of cytoplasm (c). Magnification $\times 10,000$. 


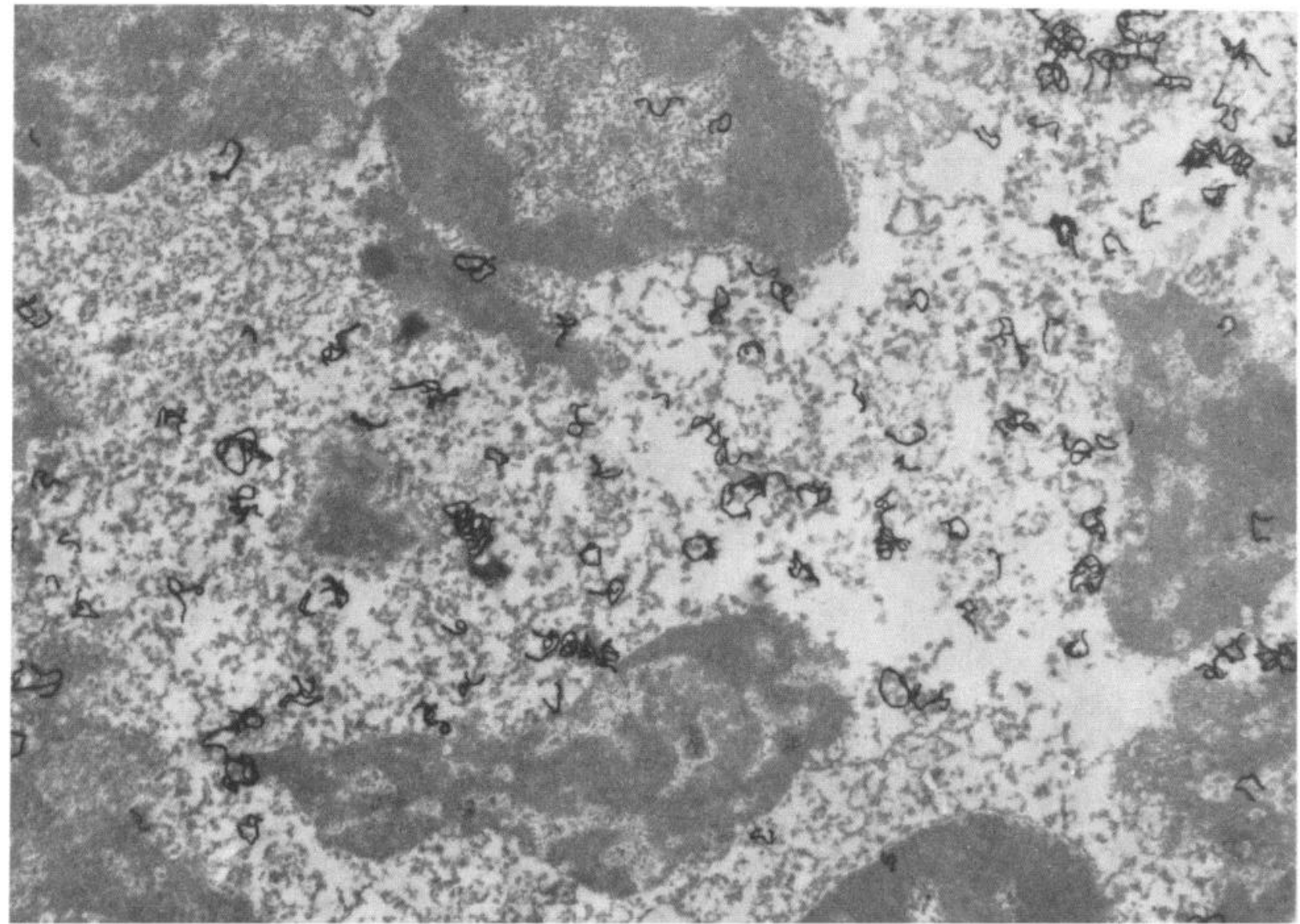

Figure 6. Autoradiograph of a nuclear pellet of PC12 cells incubated with $100 \mathrm{ng} / \mathrm{ml}$ of ${ }^{125} \mathrm{I}-\mathrm{NGF}$ for $1 \mathrm{~d}$ in suspension in PBS/ AG. This typical autoradiograph shows the impurity of this fraction. Broken nuclei and the distribution of silver grains mainly over the unidentifiable material between the nuclei are evident. Note the absence of an accumulation of grains over the remaining nuclear membrane. Magnification $\times 10,000$.

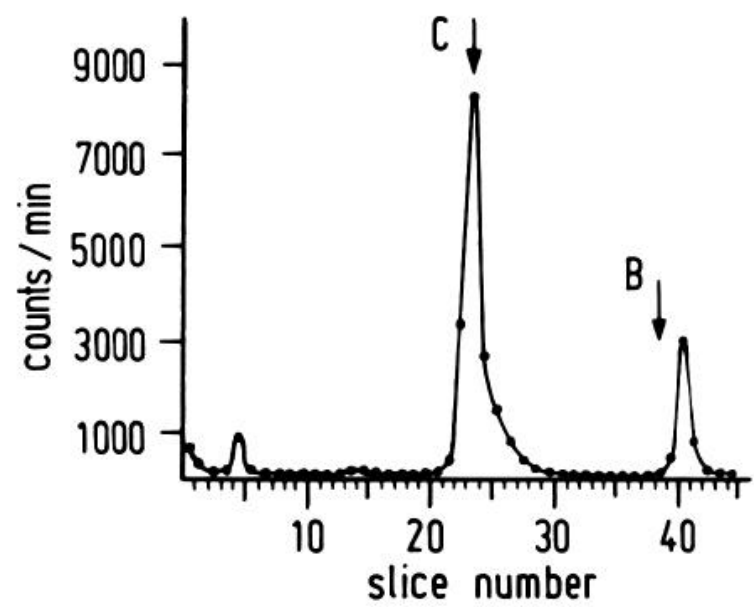

Figure 7. Electrophoretic profile of ${ }^{125} \mathrm{I}-\mathrm{NGF}$ associated with $\mathrm{PC} 12$ cells after an incubation with $100 \mathrm{ng} / \mathrm{ml}$ of ${ }^{125} \mathrm{I}-\mathrm{NGF}$ in a monolayer culture in medium supplemented with serum for 1 d. After the incubation, cells were washed three times with PBS/AG, lysed with SDS and $\beta$-mercaptoethanol, and subjected to electrophoresis on an SDS-polyacrylamide gradient gel $(12.5$ to $22.5 \%)$. The unfixed gel was cut in 2 -mm slices which were counted in a Gamma counter. Bromphenol blue $(B)$ and cytochrome $c(C)$ were used as internal markers. without a subsequent transfer to the nucleus (Schwab and Thoenen, 1977; Schwab, 1977; Claude et al., 1979; Schwab et al., 1979). On the other hand, light microscopic autoradiography and immunofluorescence (Marchisio et al., 1980) as well as cellular fractionation studies with PC12 cells (Yankner and Shooter, 1979) suggested a very substantial transfer of NGF to the nuclear chromatin and nuclear membrane. We now have demonstrated (using both quantitative EM autoradiography and subcellular fractionation) that, also in PC12 cells between $1 \mathrm{hr}$ and $8 \mathrm{~d}$ after exposure, NGF is localized at the plasma membrane and cytoplasmic compartments. No evidence was found for a selective accumulation of ${ }^{125} \mathrm{I}-\mathrm{NGF}$ in the nuclear chromatin and in the nuclear membrane compartment, provided that the cells were grown under adequate culture conditions. In view of the large proportion of grains obviously attributable to lysosomes (e.g., Figs. 1 and 4) and recent evidence (Heumann et al., 1981) for the absence of functional NGF in the free cytoplasm of PC12 cells, a quantitative localization of internalized $\mathrm{NGF}$ at cytoplasmic organelles was not performed. In monolayer cultures exposed to $100 \mathrm{ng} / \mathrm{ml}$ of ${ }^{125} \mathrm{I}-\mathrm{NGF}$ for $1 \mathrm{hr}$ to $8 \mathrm{~d}$, the proportion of ${ }^{125} \mathrm{I}-\mathrm{NGF}$ found in the nuclear fraction varied between 0.5 and $2 \%$ (Table II). The highest value was reached after $24 \mathrm{hr}$ rather than 
after $8 \mathrm{~d}$, the time necessary for all of the pheochromocytoma cells to show prominent fiber outgrowth. It must be pointed out that the values of 0.5 to $2 \%$ are within the limits of the accuracy of the method, as indicated by the standard deviations (Table II), and therefore, no conclusions may be drawn as to their significance. The results of the quantitative EM autoradiography also provided no evidence for a substantial accumulation of NGF in the nuclear compartment or in the nuclear membrane (Fig. 2; Table I). If a selective transfer of NGF to the nuclear membrane compartment had taken place, then a symmetrical distribution of the grains over the nuclear membrane would be expected, according to the distribution of grains from a line source of radiation (Salpeter et al., 1977). The asymmetrical distribution of the grains over the nuclear membrane (Fig. 3) strongly suggests that the grains appearing in this compartment result from radioactivity located in the residual cytoplasmic compartments, reflecting the distribution characteristics in a border area between an "accessible" (cytoplasmic) and a "nonaccessible" (nuclear) compartment. This interpretation also is supported by the fact that labeled lysosomes are enriched in the perinuclear region (Figs. 1 and 4).

The present study also shows that the subcellular distribution of ${ }^{125} \mathrm{I}-\mathrm{NGF}$ in PC12 cells grown in suspension under regular culture conditions does not provide any evidence for a nuclear accumulation, and therefore, the possibility that the suspension versus substrate-attached culture conditions have a significant influence on the subcellular distribution of NGF may be excluded. However, when the cells were kept in suspension, as described by Yankner and Shooter (1979), in phosphatebuffered saline supplemented with glucose and bovine serum albumin (PBS/AG), there was a very marked accumulation of about $60 \%$ of the total radioactivity in the nuclear fraction after $24 \mathrm{hr}$ incubation in $100 \mathrm{ng} / \mathrm{ml}$ of ${ }^{125} \mathrm{I}-\mathrm{NGF}$ and about $25 \%$ after incubation with $5 \mathrm{ng} / \mathrm{ml}$ of ${ }^{125}$ I-NGF (Table II). However, the morphology of the PC12 cells kept in PBS/AG differed markedly from that of cells kept in serum-containing medium (Fig. 5). Those cells grown in suspension in serum-containing medium had the same healthy appearance as the cells grown in monolayers. In contrast, the PC12 cells kept in phosphate-buffered saline with glucose and bovine serum albumin showed signs of various degrees of damage within the first $24 \mathrm{hr}$ of culture (i.e., condensation of the nuclear chromatin and dilatation of the space between the inner and outer nuclear membrane (Fig. 5a)). After $48 \mathrm{hr}$, the majority of the cells were in the process of degeneration. Accordingly, the nuclear pellet of cells incubated for $24 \mathrm{hr}$ in PBS/AG contained a heterogeneous population of nuclei of varying degrees of damage. Silver grains due to the ${ }^{125}$ I-NGF were located preferentially over damaged nuclei or over material between the nuclei whose origin could not be identified (Fig. 6). There was no evidence for a selective accumulation of ${ }^{125} \mathrm{I}-\mathrm{NGF}$ over the nuclear membranes.

The results of the present experiments demonstrate that there is no substantial accumulation of NGF in the nuclear compartment of PC12 cells unless the cells are kept under inadequate conditions so that they exhibit distinct morphological signs of cellular damage. Thus, the apparent nuclear accumulation of NGF is not a reflection of an essential physiological process but rather a consequence of cellular damage. The results of this study are also in contrast to the suggested localization of NGF within the nucleus of PC12 cells inferred from light microscopic methods (Marchisio et al., 1980). We consider, however, that light microscopic autoradiography of whole cells and immunofluorescence have a resolution too low to permit an unambiguous distinction to be made between perinuclear and intranuclear localizations, in particular in view of the heavy labeling of lysosomes preferentially localized in the perinuclear area.

Although these and the former studies on rat sympathetic neurons (Schwab, 1977; Schwab and Thoenen, 1977; Claude et al., 1979; Schwab et al., 1979) exclude a transfer of substantial quantities of NGF to the nuclear chromatin and to the nuclear membrane, they do not exclude the possibility that small quantities of NGF, undetectable by the experimental methods used in these studies, do reach these compartments to exert a biological effect. This assumption has, however, been disproved recently by the observation that $\mathrm{NGF}$, when injected into PC12 cytoplasm, subsequently entered the nuclear compartment but exerted no biological effects (Heumann et al., 1981). Correspondingly, the injection of antibodies to $\mathrm{NGF}$ into the cytoplasm did not interfere with the membrane-mediated biological effects of NGF.

The possibility remains that NGF could find access to the perinuclear space by fusion of endocytotic vesicles with the nuclear membrane which is continuous with the rough endoplasmic reticulum. However, to our knowledge, a fusion of endocytotic vesicles with the nuclear membrane or other parts of the rough endoplasmic reticulum has never been observed. The fact that the rough endoplasmic reticulum is in continuous connection with the perinuclear membrane offers a plausible explanation for the specific binding of NGF to purified nuclei (Andres et al., 1977; Yankner and Shooter, 1979): since the polypeptide part of the NGF receptor has to be synthesized by membrane-bound ribosomes in the rough endoplasmic reticulum, it is conceivable that NGF receptors are present within the nuclear membrane. They then become accessible if the continuous closed compartment formed by the perinuclear membranes and the rough endoplasmic reticulum is disrupted by the purification procedure of the nuclei when the inner, noncytoplasmic surface of the nuclear membrane is exposed.

Our results suggest that NGF exerts its effects in PC12 cells, as in sympathetic neurons, through an interaction with its receptor on the plasma membrane rather than by a transfer to the nuclear membrane or the nuclear chromatin. Furthermore, the results of the present investigation are supported by a study of Schechter and Bothwell (1981) which was published during the preparation of this paper. They demonstrated that only 1 to $2 \%$ of the ${ }^{125} \mathrm{I}-\mathrm{NGF}$ internalized into PC12 cells was present in a nuclear preparation produced by the method of Yankner and Shooter (1979) if the cells had been cultured in the presence of serum. In addition, evidence was presented that the amount of ${ }^{125}$ I-NGF in these nuclear preparations was correlated with the amount of extranuclear filamentous matrix present.

After submission of this paper, a study by Shooter et al. (1981) was published which demonstrated that the 
proportion of internalized ${ }^{125} \mathrm{I}-\mathrm{NGF}$ accumulating in nuclear fractions of PC12 cells grown in monolayer cultures using Dulbecco's modified Eagle's medium/bovine serum albumin as a medium is much lower (between 3 and $11 \%$ of the totally bound NGF after 1 and $6 \mathrm{~d}$ in culture) than reported previously (50 to $60 \%$ of totally bound NGF after $1 \mathrm{~d}$ in culture) for cells cultivated in PBS/bovine serum albumin (Yankner and Shooter, 1979). No morphological evidence for the presence of NGF in the nucleus or for the purity of the nuclear fraction and the absence of cell damage under these culture conditions was presented. Since the subcellular fractionation procedure used by Yankner and Shooter (1979) was not optimal as shown by Schechter and Bothwell (1981) and the present study (see Fig. 6), the evidence for the existence of a transfer of NGF to the nucleus of PC12 cells under physiological conditions cannot be regarded as being convincing. As all of the investigations on the physiological effects of NGF on PC12 cells have been performed in serum-containing medium, in which no measurable transfer to the nuclear chromatin and the nuclear membrane can be demonstrated, we conclude that such a transfer of NGF to the nucleus cannot be essential for its biological action.

\section{References}

Andres, R. Y., I. Jeng, and R. A. Bradshaw (1977) Nerve growth factor receptors: Identification of distinct classes in plasma membranes and nuclei of embryonic dorsal root neurons. Proc. Natl. Acad. Sci. U. S. A. 74: 2785-2789.

Bocchini, V., and P. U. Angeletti (1969) The nerve growth factor: Purification as a 30,000 -molecular-weight protein. Proc. Natl. Acad. Sci. U. S. A. 64: 787-794.

Burstein, P. E., and L. A. Greene (1978) Evidence for RNA synthesis-dependent and -independent pathways in stimulation of neurite outgrowth by nerve growth factor. Proc. Natl. Acad. Sci. U. S. A. 75: 6059-6063.

Caro, L. G., and R. P. Van Tubergen (1962) High resolution autoradiography. I. Methods. J. Cell Biol. 15: 173-188.

Claude, P., D. A. Dunis, and E. Hawrot (1979) Binding and uptake of ${ }^{125}$ I-nerve growth factor by dissociated sympathetic neurons in culture: Localization by electron microscopic autoradiography. J. Cell Biol. 83: 632.

Dumas, M., M. E. Schwab, and H. Thoenen (1979) Retrograde axonal transport of specific macromolecules as a tool for characlerizing nerve terminal membranes. J. Neurobiol. 10: 179-197.

Edgar, D., and H. Thoenen (1978) Selective enzyme induction in a nerve growth factor-responsive pheochromocytoma cell line (PC12). Brain Res. 154: 186-190.

Fenton, E. L. (1970) Tissue culture assay of nerve growth factor and of the specific antiserum. Exp. Cell Res. 59: 383-392.

Greene, L. A., and A. Rukenstein (1981) Regulation of acetylcholinesterase by nerve growth factor. Role of transcription and dissociation from effects on proliferation and neurite outgrowth. J. Biol. Chem. 256: 6363-6367.

Greene, L. A., and E. M. Shooter (1980) The nerve growth factor: Biochemistry, synthesis, and mechanism of action. Annu. Rev. Neurosci. 3: 353-402.

Greene, L. A., and A. S. Tischler (1976) Establishment of a noradrenergic clonal line of rat adrenal pheochromocytoma cells which respond to nerve growth factor. Proc. Natl. Acad. Sci. U. S. A. 73: 2424-2428.
Hendry, I. A., K. Stöckel, H. Thoenen, and L. L. Iversen (1974a) The retrograde axonal transport of nerve growth factor. Brain Res. 68: 103-121.

Ilendry, I. A., R. Stach, and K. Herrup (1974b) Characteristics of the retrograde axonal transport system for nerve growth factor in the sympathetic nervous system. Brain Res. 82: 117128.

Heumann, R., M. Schwab, and H. Thoenen (1981) A second messenger required for nerve growth factor biological activity? Nature 292: 838-840.

Iversen, L. L., K. Stöckel, and H. Thoenen (1975) Autoradiographic studies of the retrograde axonal transport of nerve growth factor in mouse sympathetic neurons. Brain Res. 88 : 37-43.

Johnson, E. M., R. Y. Andres, and R. A. Bradshaw (1978) Characterization of the retrograde transport of nerve growth factor using high specific activity $\left({ }^{125} \mathrm{I}\right)$ nerve growth factor. Brain Res. 150: 319-333.

I evi, A., Y. Shechter, E. J. Neugeld, and J. Schlessinger (1980) Mobility, clustering, and transport of nerve growth factor in embryonal sensory cells and in a sympathetic neuronal cell line. Proc. Natl. Acad. Sci. U. S. A. 77: 3469-3473.

Marchalonis, J. J. (1969) An enzymic method for the trace iodination of immunoglobulins and other proteins. Biochem. J. 113: 229-305.

Marchisio, P. C., L. Naldini, and P. Calissano (1980) Intracellular distribution of nerve growth factor in rat pheochromocytoma PC12 cells: Evidence for a perinuclear and intranuclear location. Proc. Natl. Acad. Sci. U. S. A. 77: 1656-1660.

Rohrer, H., and Y. A. Barde (1981) Presence and disappearance of NGF receptors on sensory neurons in culture. Dev. Biol. 89: 309-315.

Salpeter, M. M., H. C. Fertuck, and E. S. Salpeter (1977) Resolution in electron microscope autoradiography. III. Iodine-125, the effect of heavy metal staining, and a reassessment of critical parameters. J. Cell Biol. 72: 161-173.

Schechter, A. L., and M. A. Bothwell (1981) Nerve growth factor receptors on $\mathrm{PC} 12$ cells: Evidence for two receptor classes with differing cytoskeletal association. Cell 24: 867874.

Schubert, R., and C. Whitlock (1977) Alteration of cellular adhesion by nerve growth factor. Proc. Natl. Acad. Sci. U. S. A. 74: $4055-4058$.

Schwab, M. E. (1977) Ultrastructural localization of a nerve growth factor-horseradish peroxidase (NGF-HRP) coupling product after retrograde axonal transport in adrenergic neurons. Brain Res. 130: 190-196.

Schwab, M. E., and H. Thoenen (1977) Selective trans-synaptic migration of tetanus toxin after retrograde axonal transport in peripheral sympathetic nerves: A comparison with nerve growth factor. Brain Res. 122: 459-474.

Schwab, M. E., K. Suda, and H. Thoenen (1979) Selective retrograde transsynaptic transfer of a protein, tetanus toxin, subsequent to its retrograde axonal transport. J. Cell Biol. 82: $798-810$.

Shooter, E. M., B. A. Yankner, G. E. Landreth, and A. Sutter (1981) Biosynthesis and mechanism of action of nerve growth factor. Recent Prog. Horm. Res. 37: 417-439.

Suda, K., Y. A. Barde, and H. Thoenen (1978) Nerve growth factor in mouse and rat serum: Correlation between bioassay and radioimmunoassay determinations. Proc. Natl. Acad. Sci. U. S. A. 75: 4042-4046.

Thoenen, H., and Y. A. Barde (1980) Physiology of nerve growth factor. Physiol. Rev. 60: 1284-1335.

Yankner, B. A., and E. M. Shooter (1979) Nerve growth factor in the nucleus: Interaction with receptors on the nuclear membrane. Proc. Natl. Acad. Sci. U. S. A. 76: 1269-1273. 